International Journal of Applied Linguistics \& English Literature

ISSN 2200-3592 (Print), ISSN 2200-3452 (Online)

Vol. 1 No. 7; November 2012 [Special Issue on Applied Linguistics]

\title{
Iranian Junior High school English Book Series (Right Path to English) Weighted against Material Evaluation Checklists
}

\author{
Farhad Golpour \\ Islamic Azad University, Fouman and Shaft Branch, English Department, Fouman, Iran \\ Tel: $013272309042 \quad$ E-mail: GolpourF@gmail.com
}

Received: 14-10- 2012

Accepted: 09-11- 2012

Published: 25-11- 2012

doi:10.7575/ijalel.v.1n.7p.170

URL: http://dx.doi.org/10.7575/ijalel.v.1n.7p.170

\begin{abstract}
Choosing a course textbook is an overwhelming task for both teachers and administrators. The aim of this study was to evaluate Iranian junior high school textbook series base on validated criteria. For this purpose a careful analyzing textbook evaluation checklists suggested by Sheldon (1984) skierso (1991) and Tucker (1992) was picked out. Among proposed criteria, eighteen critical features were selected to analyze Iranian junior high school series written by Birjandi in (1991). The Criteria were applied to the series analytically by researcher to examine the materials. The criteria in a form of questionnaire given to 15 experienced teachers who were teaching mentioned series for more than ten years. The gathered data revealed that it lacks appropriate layout and physical characteristics, materials have not be recycled, not all skills have been considered equally, emphasis is on grammatical points which practiced through speaking and listening. Moreover; recordings are artificial, no attention is paid to students needs and topics are out of date and boring .Also audio-visual materials, teachers' guide and communicative tasks seems to be forgotten by writer. Therefore; all eighteen features except vocabulary lists, availability of glossary and lots of grammatical points have not been considered a lot. That is, students' interests have been ignored totally and little communicative issues have been regarded in these series. In fact, at end of this determined time students would be proficient at structural points with no efficiency at communication. These findings can be helpful for curriculum designers, textbook writers to design some valuable textbooks that are useful for teachers to teach language communicatively.
\end{abstract}

Keywords: Junior High school, Evaluation, book series, criteria

\section{Introduction}

Selecting a course text book is a tough job for both teachers and administrators. Skierso asserts that "importance of the text book in an English as a second language class makes the selection of process crucial "(1991, p. 432). Sheldon emphasizes that "selection of course book is an executive educational decision in which there is considerable professional, financial and even political investments " $(1988$, p.237).The publication of the first English textbook for Iranian schools dates back to 1937 for about twenty years, different texts such as Essential English (Eckersley, 1952) Oxford series (Hornby, 1954) Modern English (Dorry, 1950) were utilized at a national level. Before utilization of Right Path to English series written by Birjandy(1991), several years Graded English has been used. Teaching junior high school books series for ten years and evaluating these series at different universities and teacher training center, researcher decided to examine and evaluate them based on evaluation checklists proposed by Coleman ( 1985 ) skierso ( 1991 ), Tucker ( 1992 ), to some extent on his own experiences and his university students' opinions who completed these courses . In writing a course book series a through coverage of all language skills, that is speaking, listening, writing and reading and also components of language such as grammar, pronunciation and vocabulary called syllabus should be considered. By a brief review on different syllabuses such as Nunan (1993) categorization of grammatical, notional and functional, and task-based syllabuses we can understand that a course book writer that intends his learners to be proficient in language learning, his book should be involved the following features as Richard (2002) identifies: 1. An integrated multi skills 2 . Contemporary real world topics 3 . Practical authentic conversational language 4.Grammar taught in communicative contexts 5. Natural listening exercises with various accents 6 . Maximum opportunities for guided speaking practices 7. Students - friendly and teacher - friendly design 8 . Fun to teach and use in the classroom. Therefore, a researcher by consideration of checklist tries to have a complete evaluation upon these series. 
International Journal of Applied Linguistics \& English Literature

ISSN 2200-3592 (Print), ISSN 2200-3452 (Online)

Vol. 1 No. 7; November 2012 [Special Issue on Applied Linguistics]

1.1Statement of problem and purpose of the study

There have been many studies investigated some text books based on evaluation checklists. Skierso (1991) states that before teaching a text book, teachers should consider some points such as having some back ground knowledge and culture?, What is their motivation and what are their reasons for learning a language, whether they are learning English for specific purpose or just for communication. For book selection, choosing vocabulary, grammatical structure and topic should be based on the interests and needs of students. And also exercises and activities must lead learners along their goals and purposes. Researcher wants to know why it is more than twenty years that Iranian English teachers taught Right Path to English book series at junior high school level but most of them don't satisfy by its content. To be aware of problems within these series researcher carefully analyzed series based on proceeding mentioned checklist.

\subsection{Significant of study}

Some studies have focused on evaluation of specific series. Hutchinson (1987) analyzed guidebook written by Hensley (1997). Amerian(1987)has compared the first two books of Right Path to English Series and the Graded English Series. Based on his analysis he stated that graded English suffers from two following defects: 1).The content is qualitatively insufficient and 2) the structural drills are quantitatively insufficient. The most important evaluation is that of Soodmand (2008) that has analyzed new interchange (third edition) text book. He has done this analysis and concluded that this course book is rich in various aspects such as using authentic text, having good topics and different tasks and invaluable illustration. But Iranian series are seriously weak in different aspects. So writer decided to have an analysis to classify some important points and to mention merits and demerits of these series. Hence this analysis can be helpful for syllabus writers and curriculum designers to pay more attention to content of series and make some changes to remove the problems that teachers encounter when teaching.

Knowing specific features of series can be useful for teachers to get a new view of course book, moreover, by making some changes and providing new topics and tasks teaching can be easy and interesting for them. In addition, teachers can understand why their students after three years of teaching even are not able to introduce themselves in English. Besides, by being aware of research results, University students can write some articles and researchers inform decision makers to concentrate more on education and content of course books.

\subsection{Procedure}

Researcher, by giving a questionnaire to some experienced teachers tried to gather their ideas about Right Path to English course book. By providing these data, researcher analyzed each item carefully and with more sensitivity to get valuable results. Furthermore, to have realistic and applicable results, researcher used clear - cut criteria from different resources that have been used by other researchers (mentioned later).

\subsection{Checklist}

There are many checklists for book evaluation - we cannot say one is better than other, on the other hand, by combination of them and using precious features of each to make an appropriate checklist will be more useful. so researcher used salient criteria from following checklist such as seldom ( 1988 ), Skierso ( 1991 ), Coleman ( 1985) and Tucker ( 1992 ) and tried to provide a good checklist.

\section{Method}

Method of this study is descriptive. Procedure and materials included in this study, too. Here researcher by using a checklist analyzed three English Junior high school course books; in addition, not only qualitative but also quantitative methods have been used.

\section{Materials}

Materials used in this study included a textbook evaluation checklist by Skierso (1991), Hutchinson (1987), Hensley (1997) and junior high school book series (book one, two, and three). After careful studying, researcher selected the following significant questions.

1. Are the lay - out and physical characteristics of the series interesting and attractive?

2. Are the materials too biased and culture - specific?

3. Are review or progress tests included in the series?

4. Are the instruction for activities and exercises clear enough? 
International Journal of Applied Linguistics \& English Literature

ISSN 2200-3592 (Print), ISSN 2200-3452 (Online)

Vol. 1 No. 7; November 2012 [Special Issue on Applied Linguistics]

5. Is a glossary or a vocabulary list included at the end of the book or throughout the book?

6. Are the materials graded and recycled?

7. Have all skills ( listening, speaking, reading and writing ) and components of language ( e .g . grammar , vocabulary and pronunciation ) been incorporated into the series?

8. Are the recordings for listening section "authentic" and not artificial?

9. Do the materials correspond to the learners needs and match their aims and objectives?

10. Do the design and content of the series suggest ease of use and encourage learner's motivation?

11. Do the books develop learners' socio - pragmatic and strategic competencies?

12. Are teacher guides available? Are they helpful in achieving the objectives of the course?

13. Are power relations between the characters in the units of equal rank?

14. Are appropriate visual materials available for the series?

15. Are the topics and tasks in the series interesting and attractive?

16. Is grammar practiced and presented well and systematically in the units?

17. Are there enough vocabulary items in each unit?

18. Does the series encourage learners to develop their own vocabulary learning strategies and what vocabulary learning strategies are recommended in the series?

\section{The researcher's scrutiny}

\subsection{The lay out and physical characteristics}

Is the series interesting and attractive? Are the physical characteristic well - organized?

i Table 1. (The lay out and physical characteristics)
\begin{tabular}{|c|c|c|c|c|}
\hline 1 & 2 & 3 & 4 & 5 \\
\hline 75 & 25 & 0 & 0 & 0 \\
\hline
\end{tabular}

In order to make a book interesting, there should be some colourful illustration and this leads to contextualization of materials. The writer of junior high school English course book has tried to make the series interesting by some colourful pictures. For every section of each unit, a certain colour has been used; however the pictures don't seem to attract students' attention. Base on the analysis of questionnaire $81 \%$ of English teachers selected item one. It means that after ten year teaching, they concluded that this course book is not interesting at all. Using real pictures of objects and people can be much more elaborating and interesting to the students. Moreover, blank space for writing exercises is not enough. The cover of the book is poorly bonded but researcher recommends a hard cover and a plastic, impregnated fabric which provides the most durable cover. Because such covers are stain and dirt resistant as well as washable.

\subsection{Culture Component}

Is the material in the series too biased or culturally specific? Is the material inclusive of all cultures or culture specific?

Table 2. (Culture Component)

\begin{tabular}{|c|c|c|c|c|}
\hline 1 & 2 & 3 & 4 & 5 \\
\hline 75 & 25 & 0 & 0 & 0 \\
\hline
\end{tabular}

The materials in the series are too biased and culture specific. That is, it is bound to Iranian culture. The name of the characters (Ali, Reza, Mrs Irani , Parvin, etc ), the name of cities and place (Shiraz, Namak Abrood, etc ), and the way characters are dressed are all evidence to show bias towards the Iranian culture. It should be noted that language and culture are not separate from each other but they are complementary to each other; one cannot claim that he wants to learn a language but he doesn't like to learn culture of the people speaking that language. Another point is that although promoting a culture through an international language -no matter how rich that culture is - 


\section{International Journal of Applied Linguistics \& English Literature \\ ISSN 2200-3592 (Print), ISSN 2200-3452 (Online)}

Vol. 1 No. 7; November 2012 [Special Issue on Applied Linguistics]

sounds logical, what the writer of the series have aimed is to promote the Iranian culture to Iranian students - that is , to those who are already familiar with culture of their own country because of living in the society . Therefore; introducing a language with it is cultural points always sounds move interesting and motivating for learners.

\subsection{The inclusion of review or progress tests}

Are there any review sections or progress tests available in the materials?

Table 3. (The inclusion of review or progress tests)

\begin{tabular}{|c|c|c|c|c|}
\hline 1 & 2 & 3 & 4 & 5 \\
\hline 50 & 50 & 0 & 0 & 0 \\
\hline
\end{tabular}

Unlike some other international series in which a progress test is included after every two units, junior high school book series includes few numbers of review tests that is, one review test in volume one, three review tests in volume two, and three review tests in volume three. By comparison, in new interchange thirty - two sections entitled "progress check" can be observed but in Iranian series just seven review tests in three volumes involves twenty nine lessons are noticeable. As table shows 50 percent of teachers selected item two and half of them selected item three. It can be concluded that instead of some shortages teachers satisfy with them.

\subsection{Clarity of the presentation and instructions}

Are the instructions clear enough?

Table 4. (Clarity of the presentation and instructions)

\begin{tabular}{|c|c|c|c|c|}
\hline 1 & 2 & 3 & 4 & 5 \\
\hline 13 & 87 & 0 & 0 & 0 \\
\hline
\end{tabular}

The preceding table demonstrates that instructions of exercises are not clear. That is, students by following given examples easily understand how to do their exercises but by omitting model, students completely get confused. That is, most of teachers- 80 percent -indicated that instructions are so weak. If they use the same instructions in their exam paper, it will be misleading such as page 45 -example $\mathrm{C}$ book three. Consequently, instructions must be clear and understandable for students to do the exercises without giving a model.

4.5 Inclusion of a vocabulary list or a glossary

Is a glossary both at the end of each lesson and at the end of each unit?

Table 5. (Inclusion of a vocabulary list or a glossary)

\begin{tabular}{|c|c|c|c|c|}
\hline 1 & 2 & 3 & 4 & 5 \\
\hline 0 & 0 & 0 & 50 & 50 \\
\hline
\end{tabular}

There is a glossary both at the end of each lessen and at the end of each book. These course books have an advantage over other series in that, they include phonetic representation of words accompanied by each word. Another advantage of series is that, before the glossary, two pages are included among which one is devoted to introducing vowels, consonants, and diphthongs, and the other is devoted to presenting irregular verbs and past forms of them, because of these advantages, almost all teachers adjust the preceding points.

\subsection{The grading and sequencing of the materials}

How are the materials graded? Are they recycled? Is there any variety in the exercise?

Table 6. (The grading and sequencing of the materials)

\begin{tabular}{|c|c|c|c|c|}
\hline 1 & 2 & 3 & 4 & 5 \\
\hline 13 & 87 & 0 & 0 & 0 \\
\hline
\end{tabular}

The writer of English course books have tried to consider the cognitive principle of moving from known to unknown and moving from simple to complex. As it can be observed obviously in the series, all units start with 
International Journal of Applied Linguistics \& English Literature

ISSN 2200-3592 (Print), ISSN 2200-3452 (Online)

Vol. 1 No. 7; November 2012 [Special Issue on Applied Linguistics]

teaching alphabets, then simple words and moves toward teaching complete sentences and expressions. However, it seems that series lack enough recycling and reviewing of words. Introducing so many words in the glossary

(e.g. book 3. page 64. 43 new words) at the end of each unit can be regarded as an evident to prove this shortcoming. As matter of fact, students usually forget around 80 percent of new words after 24 hours (skierso, 1991). Regarding the verities of the exercises, it should be mentioned that unfortunately, there is no variety in exercises and all units follow the same pattern of presenting the lesson through drilling. All exercises are designed to improve students' syntactic knowledge. There are many controlled practices but no creative or communicative activities and tasks exist. Just a given model precedes each exercise which guides students to follow the model. The shortcomings may encourage all teachers to intensify that the series haven't been arranged systematically.

\subsection{The inclusion of multi-skills and components in the materials}

Which one of the following aspects of language is covered in the series: grammar, vocabulary or pronunciation? Which skills listening, speaking, writhing, reading are emphasized?

Table7. (The inclusion of multi-skills and components)

\begin{tabular}{|c|c|c|c|c|}
\hline 1 & 2 & 3 & 4 & 5 \\
\hline 13 & 87 & 0 & 50 & 50 \\
\hline
\end{tabular}

Junior high school English books have been developed based on structural syllabus and rely on learning oral aspect of language through drills. As evidence, generally every lesson consists of two dialogues, one pattern, three kinds of drill (one - slot, two slots of two substitution drills), five speaking exercises, three controlled writing exercises and one reading text with some wh-questions. Mostly oral proficiency is considered a lot, although little attention is on listening comprehension. No creative activity for improving speaking and listening skills exist. Besides, controlled writing never leads to learning writing, and including a reading text without adding creative activities, title and picture, never improve students reading ability. Regarding components, grammar and vocabulary received more attention although less emphasis is on pronunciation. In general, all teachers have indicated series have not been involved all four skills and components.

\subsection{Authenticity of listening recordings}

Is listening recording authentic or artificial?

Table 8. (Authenticity of listening recordings)

\begin{tabular}{|c|c|c|c|c|}
\hline 1 & 2 & 3 & 4 & 5 \\
\hline 83 & 17 & 0 & 0 & 0 \\
\hline
\end{tabular}

Since the scripts and recordings of series have not been provided by using of origin texts, they cannot be regarded as authentic ones. Moreover, questions and answers in dialogues seem to be unusual and artificial. Sentences of conversation emphasize on presentation of grammatical points. For instance in book three, lesson one Amir asks Ali: There's a on the ground. Is it your wallet? Ali: no, it isn't .The colour of my wallet is brown, but this one is yellow. Amir: perhaps it's Ahmad's. He is there at the bus stop. Ali: I don't know Ahmad. What does he look like? Amir: He's tall and thin and has short black hair.

Clearly speaking, this situation rarely happens. Moreover; when someone standing on the bus stop and his friend is referring to him, it does not need him explain about his friend's appearance. A dialogue should be base on real situations and using idioms and idiomatic expressions are recommended. Teachers' views also emphasize preceding explanation. In fact, the purpose of preceding conversation is to improve students' grammatical knowledge of possession and adjective.

\subsection{The correspondence of the materials to students needs}

Do the materials correspond to the learners needs?

Table9. (The correspondence of the materials to students needs)

\begin{tabular}{|c|c|c|c|c|}
\hline 1 & 2 & 3 & 4 & 5 \\
\hline 50 & 50 & 0 & 0 & 0 \\
\hline
\end{tabular}




\section{International Journal of Applied Linguistics \& English Literature}

ISSN 2200-3592 (Print), ISSN 2200-3452 (Online)

Vol. 1 No. 7; November 2012 [Special Issue on Applied Linguistics]

Since the goal of language learning is communication, the series cannot meet this goal. As mentioned before, the series are developed base on structural view of language learning and its emphasis is on oral proficiency through drills .These books cannot correspond to learners' needs. Since focusing on grammar leads students gain accuracy then fluency. Researcher asked third grade junior high school students to introduce themselves in English both in the forms of writing and speech. None of thirty five students that researcher asked could write a correct sentence or write a meaningful one, in comparison to those who attended in private institutions could do well. As conclusion dialogue should be topic- based, relating to a real situations and being along with learners' interests and needs.

\subsection{User - friendliness of the design and content of the materials}

Does the use of design of the book heighten and sustain learner's motivation?

Table10. (User - friendliness of the design)

\begin{tabular}{|c|c|c|c|c|}
\hline 1 & 2 & 3 & 4 & 5 \\
\hline 38 & 62 & 0 & 0 & 0 \\
\hline
\end{tabular}

Some factors such as interesting topics, delightful group and pair work activities, authentic conversation, real pictures and illustration, attractive cover and communicative activities can keep students motivated. In comparison to other international series such as Interchange series that in each unit of it, an interesting topic attracts student attention, in junior course books no appealing topics can been seen, just some boring grammatical points within dialogue and drill patterns with controlled exercises are observable. As table 10 shows, all participants intensified the weakness of series in this respect.

\subsection{The series developing socio - pragmatic and strategic competencies}

Does the book aim to maximize learner's opportunities to develop socio - pragmatic and strategic competencies?

Table11. (developing socio - pragmatic and strategic competencies)

\begin{tabular}{|c|c|c|c|c|}
\hline 1 & 2 & 3 & 4 & 5 \\
\hline 50 & 50 & 0 & 0 & 0 \\
\hline
\end{tabular}

Exercises and drills in the series are too controlled to let the students develop helpful competencies for communication, it's due to the fact that series have been developed base on the structural view of linguists and behavioural view of psychology that emphasizes on learning language through repetition. The exercises are too mechanical to meet communicative aspect of language learning. A national series must entice learners to improve their knowledge of communication and social acts. Table11 approves researcher opinion.

\subsection{Availability and effectiveness of teacher guides}

Is the teacher guide available? Is the teacher guide effective and successful in achieving its goal?

Table12. (Availability of teacher guides)

\begin{tabular}{|c|c|c|c|c|}
\hline 1 & 2 & 3 & 4 & 5 \\
\hline 100 & 0 & 0 & 0 & 0 \\
\hline
\end{tabular}

Unfortunately, there is no teacher guides to instruct the teachers how to present the materials. Actually, series have been written based on structural syllabus that should be taught base on audio-lingual method.

Is an appropriate way of instructing such syllabus? As can be seen in different schools in Iran, each teacher follows his own way of teaching. A teacher guide is essential to help all teachers follow a suitable method and a certain way of presenting materials. All teachers approve lack of having a guidebook.

\subsection{Power relations between characters in the units}

Table13. (Power relations between characters)

\begin{tabular}{|c|c|c|c|c|}
\hline 1 & 2 & 3 & 4 & 5 \\
\hline 25 & 25 & 25 & 25 & 0 \\
\hline
\end{tabular}




\section{International Journal of Applied Linguistics \& English Literature}

ISSN 2200-3592 (Print), ISSN 2200-3452 (Online)

Vol. 1 No. 7; November 2012 [Special Issue on Applied Linguistics]

As Colley and Bar (1998) maintain there are few conversations, in which status and power are not relevant (p. 13). Therefore, characters' relationships are noticed carefully and chid parents relationships are common relationships in the series. it seems teachers are dubious to endorse all characters are equal, since 25 percent of them chosen lack of this feature and a quarter selected weak one and the other fifty percent of participants preferred to accept having equal relationships.

\subsection{The presentation of the skills and components in the materials}

Which of the following aspects of language should be covered in the course book: Grammar, vocabulary, pronunciation, listening, speaking, and reading or pragmatics strategies of communication?

Table 14. (The presentation of the skills and components)

\begin{tabular}{|c|c|c|c|c|}
\hline 1 & 2 & 3 & 4 & 5 \\
\hline 83 & 17 & 0 & 0 & 0 \\
\hline
\end{tabular}

Frankly speaking, writer's attention focused on grammar, other components such as vocabulary is at the service of grammar. Unlike, international series components of language help skill learning, In Iranian series just one grammatical point represented in dialogues, pattern drills, reading texts and controlled writing. For instance, simple past tense has been illustrated in lesson five reading of text in grade three books. This text suffers from interesting topic, illustration attractiveness and functional load. In addition, by having more than 10 new words and expressions make its dialogue, as mentioned before, not authentic and communicative. Because structural linguists concur by memorizing some grammatical pattern, learners will be able to learn a foreign language, this idea rejected by majority of participants.

\subsection{Availability of visual materials}

Are suitable visual materials available for the series?

Table15. (Availability of visual materials)

\begin{tabular}{|c|c|c|c|c|}
\hline 1 & 2 & 3 & 4 & 5 \\
\hline 75 & 25 & 0 & 0 & 0 \\
\hline
\end{tabular}

International series generally accompanied with audio, video CDs or cassettes, but unfortunately Iranian series deprive of having visual aids. Although, some non - native armature people recorded various tapes that can be found in all book shops. Moreover, teachers usually do not take audio devices serious. Moreover, there is not a teacher's guide to help teachers how to use these devices. As table15 shows teacher's ideas approve the preceding explanation.

\subsection{Inclusion of interesting topics and tasks}

Are the topics of and tasks in the series interesting?

Table16 (Inclusion of interesting topics and tasks)

\begin{tabular}{|c|c|c|c|c|}
\hline 1 & 2 & 3 & 4 & 5 \\
\hline 75 & 25 & 0 & 0 & 0 \\
\hline
\end{tabular}

Unlike topics in some international series such as New Headway, topic in English books of junior high school series are not interesting, attractive and up - to-date. Since a great portion of each unit is developed to introduce one or move grammatical points. As can be observed many international series include attractive topics such as fashion, sports, music and food that are tastes of youth. Table 16 reveals that none of teachers believes the series have interesting tasks and topics; on the contrary, there are some artificial sentences and dialogues that are never used by native speakers in real situations.

\subsection{Inclusion of enough vocabulary items}

Table17. (Inclusion of enough vocabulary items)

\begin{tabular}{|c|c|c|c|c|}
\hline 1 & 2 & 3 & 4 & 5 \\
\hline 0 & 25 & 75 & 0 & 0 \\
\hline
\end{tabular}


International Journal of Applied Linguistics \& English Literature

ISSN 2200-3592 (Print), ISSN 2200-3452 (Online)

Vol. 1 No. 7; November 2012 [Special Issue on Applied Linguistics]

New vocabularies have been introduced both at the end of each unit and at the end of each book. As Tucker ( 1992) declares in each unit introducing 6 up to 12 new words is recommended, while the number of new vocabularies in the series exceed 12 (volume 3 , page 64,43 new vocabularies are introduced). The main reason behind this may be the fact that vocabularies in the series are not recycled in the following units. In table 15 percent of participants indicated that the number of vocabulary is sufficient.

\subsection{Incorporation of various vocabularies learning strategy}

Table18. (various vocabularies learning strategy)

\begin{tabular}{|c|c|c|c|c|}
\hline 1 & 2 & 3 & 4 & 5 \\
\hline 83 & 13 & 0 & 0 & 0 \\
\hline
\end{tabular}

\section{Conclusion}

Providing an appropriate series for educational system of any country is compulsory, having precious series can improve learners' knowledge of a foreign language; moreover, attractive series can motivate learners in learning process. Junior high school series do not incorporate positive qualities required of a textbook based on standard checklist. Some qualities and criteria discussed above but first, enumeration of disadvantages seems rational. These shortages included lack of an appropriate lay out, suitable physical characteristics and recycled materials; in addition, not all skills have been considered equally and emphasis is on grammatical points, which were practiced through speaking and listening exercises. Moreover, recordings are artificial, no attention paid to students needs, topics are out of date, and boring. In addition, visual materials, teachers' guide and communicative tasks seem to be forgotten by writers.

Despite great number of disadvantages listed above these series, have some merits such as lists of vocabulary and many grammatical points that encourage students to memorize these points to help them improve their knowledge. Of course, adding this point seems necessary that much of the language teaching occurring through the world cannot be taken place without extensive use of textbooks. Richard (2004) mentions that the use of textbooks in teaching have advantages of providing structure and syllabus for a programme, helping standardize instruction, maintaining quality, providing variety of learning resources, providing effective language models and input. He adds depending solely on textbooks may not reflect students' needs. He adds learning how to use and adapt text books is an important part of teacher's, professional knowledge. Using textbooks from page to page without having supplementary materials is not the most satisfactory method for meeting students 'needs. Researcher suggests that teachers in terms of their students' language levels provide some additional materials to promote their student's knowledge. Consequently; curriculum designers and textbook writers must design some valuable course books that help learners to learn language communicatively or whatever learners need to earn.

\section{Suggestions}

1. It is suggested that ministry of education should support present book compilers to write a complete teachers' guide to help teachers to use a common way of material presentation with some creative options.

2. It is recommended that syllabus designers should consider new theories in language teaching and learning and new trends in syllabus writing which international series rely on them.

3. The other suggestion is also for book writers to accomplish the book with more emphasis on task-based activities and meaningful communicative information gap-based activities with enjoyable games that will lead to educated and skillful student instead of filling their minds with grammatical points.

4. The present series suffers from a valuable workbook, CD and teaching-based test that is suggested to be added to the series.

5. The needs of learners, what has been totally ignored, is another point that should be considered.

6. The other recommendation is for those who are responsible for making conditions ready for teachers. I mean giving facilities to schools and dedicating one class as a language class.

7. Suggesting that removing some grammatical tiresome exercises and replacing some puzzle and vocabulary exercises is not irrational. 
International Journal of Applied Linguistics \& English Literature

ISSN 2200-3592 (Print), ISSN 2200-3452 (Online)

Vol. 1 No. 7; November 2012 [Special Issue on Applied Linguistics]

\section{References}

Amerian, A.(1987). Comparison of Right Path to English Series with Graded English Series. Unpublished article. Birjandi, p. (1991). Right Path to English. Tehran, Karaj.

Coleman, H (1985) .Evaluating teachers guides: Do teachers guides teach teacher? In J.C, Alderson ( Ed )

Evaluation Lancaster practical papers in English language Education. vol. 6, oxford: Pergamum.

Dorry, G. N. (1950). Games for Second Language Learning. New York: McGraw-Hill.

Collie, J and bar. (1998). Evaluating and selecting EFL teaching materials. London: Heinemann.

Coleman,H.(1985).Evaluating teacher's guides: Do teacher's teach teacher? In J. C., Alderson(Ed) Evaluation.

Lancaster practical papers in English language education.Vol.6, Oxford: pergamon.

Eckersley, C. E. (1952). Essential English for Foreign Students. Book 4. London:Longmans, Green.

Hornby, A. S. (1954). Oxford Progressive English for Adult Learners. Book One .London: Oxford University Press.

Hutchinson, T. (1987). What's underneath? : An interactive view of materials evaluation . In L. E. Sheldon, (Ed). Text books and materials : problems in evaluation and development. ELT document 126, oxford: Modern English publications, The British council.

Nunan, D. (1993). Syllabus Design. Oxford University Press.

Richard. c (2004). Seeking can senses in course book evaluation. ELT Journal. 51 (1).

Rubin, s. (1987). Learner strategies: theoretical assumptions, research history and typology. In Wonden and Rubin ( Eds ). Learner strategies in language learning (pp.15 - 30), New York : prentice Hall.

Sheldon, L. E. (1987). EIT Textbooks and materials: problems in Evaluation and Development - ELT Document 126, oxford. Modern English publication : British council .

Soodmand, A.(2008). Interchange weighted against a checklist. Unpublished article.

Skierso, A. (1991). Textbook selection and evaluation. In M. Celce - Murcia (Ed.). Teaching English as a second or foreign Language (pp. 432 - 453). Boston: Heinle and Heinle publishers.

Tucker . ( 1992 ). Textbook selection and evaluation. ELT journal 42 4).

\section{Appendix}

\section{Questionnaire:}

Please answer this questionnaire of book evaluation sincerely.

\section{Totally lacking 2. Weak 3. Adequate 4. Good 5. Excellent}

1. Are the lay - out and physical characteristics of the series interesting and attractive?

1. $\bigcirc 2 . \bigcirc 3 . \bigcirc 4 . \bigcirc 5 . \bigcirc$

2. Are the materials too biased and culture - specific?

1. $О 2 . \bigcirc 3 . \bigcirc 4 . \bigcirc 5 . \bigcirc$

3. Are review or progress tests included in the series?

1. $О 2 . \bigcirc$ 3. $\bigcirc 4 . \bigcirc 5 . \bigcirc$

4. Are the instruction for activities and exercises clear enough?

1. $О 2 . \bigcirc 3 . \bigcirc 4 . \bigcirc 5 . \bigcirc$

5. Is a glossary or a vocabulary list included at the end of the book or throughout the book?

1. $\bigcirc 2 . \bigcirc 3 . \bigcirc 4 . \bigcirc 5 . \bigcirc$ 


\section{International Journal of Applied Linguistics \& English Literature \\ ISSN 2200-3592 (Print), ISSN 2200-3452 (Online) \\ Vol. 1 No. 7; November 2012 [Special Issue on Applied Linguistics]}

6. Are the materials graded and recycled?

1. $\bigcirc 2 . \bigcirc$ 3. $\bigcirc 4.05 .0$

7.Have all skills ( listening, speaking, reading and writing ) and components of language ( e . g .,grammar , vocabulary and pronunciation ) been incorporated into the series?

1. $\bigcirc$ 2. $\bigcirc$ 3. $\bigcirc 4 . \bigcirc 5.0$

8. Are the recordings for listening section "authentic" and not artificial?

1. O 2. O 3. O 4. O 5. O

9. Do the materials correspond to the learners needs and match their aims and objectives?

1. 02.03 .04 .05 .0

10. Do the design and content of the series suggest ease of use and encourage learner's motivation?

1. O 2. O 3. O 4. O 5. O

11. Do the books develop learners' socio - pragmatic and strategic competencies?

1. $\bigcirc 2 . \bigcirc 3 . \bigcirc 4.05 .0$

12. Are teacher guides available? Are they helpful in achieving the objectives of the course?

1. $\bigcirc 2$. $\bigcirc$ 3. $\bigcirc 4 . \bigcirc 5 . \bigcirc$

13. Are power relations between the characters in the units of equal rank?

1. $\bigcirc$ 2. O 3. O 4. O 5. $\bigcirc$

14. Are appropriate visual materials available for the series?

1. $\bigcirc 2 . \bigcirc 3 . \bigcirc 4 . \bigcirc 5 . \bigcirc$

15. Are the topics and tasks in the series interesting and attractive?

1. $\bigcirc 2$. О 3. O 4. O 5. O

16. Is grammar practiced and presented well and systematically in the units?

1. O 2. O 3. O 4. O 5. O

17. Are there enough vocabulary items in each unit and are there practiced will in the units?

1. O 2. O 3. O 4. O 5. O

18. Does the series encourage learners to develop their own vocabulary learning strategies and what vocabulary learning strategies are recommended in the series?

1. $\bigcirc 2$. $\bigcirc$ 3. $\bigcirc 4 . \bigcirc 5.0$

\section{Note}

i 1. Totally lacking $\quad$ 2. Weak $\quad 3$. Adequate $\quad 4$. Good $\quad 5$. Excellent 